\title{
RIBOTOS INTELEKTO RAIDOS MERGINŲ FIZINIO PAJĖGUMO KAITA DE்L RITMINĖS GIMNASTIKOS POVEIKIO
}

\author{
Diana Rèklaitienè, Jūratė Požèrienè \\ Lietuvos kūno kultūros akademija, Kaunas, Lietuva
}

\begin{abstract}
Diana Rèklaitienė. Socialinių mokslų daktarè. Lietuvos kūno kultūros akademijos Taikomosios fizinès veiklos katedros lektorè. Moksliniu tyrimų kryptis - neigaliujų reabilitacija per šokị ir gimnastika.
\end{abstract}

\section{SANTRAUKA}

Pastaruoju metu vis dar dideli rūpesti kelia ribotos intelekto raidos asmenu integravimasis, ju gyvenimo kokybe ir ugdymas. Kaip rodo praktika, daugelis pedagogu, dirbdami su ribotos intelekto raidos vaikais, pastebi tam tikru teigiamu ju fiziniu ir asmenybès pokyčiu. Todèl reikètu pabrëžti, kad vis dar stokojama tyrimu, kuriais bütu bandoma ¿vertinti taikomosios ritminès gimnastikos, kaip vieno iš taikomosios fizinès veiklos elemento, poveiki vidutiniškai protiškai atsilikusiems vaikams.

Tyrimo tikslas — nustatyti ritminès gimnastikos pratybu poveiki ribotos intelekto raidos merginu fiziniam pajegumui. Iškeltas tikslas leido apibrěžti šiuos tyrimo uždavinius: 1) parengti ritminès gimnastikos pratybu programa ribotos intelekto raidos merginu fiziniam pajègumui gerinti; 2) atskleisti ribotos intelekto raidos merginu fizinio pajègumo pokyčius dèl ritminès gimnastikos pratybu poveikio.

Buvo tiriamos ribotos intelekto raidos 18 -25 metu merginos $(n=36)$, pasirinktos atsitiktiniu netikimybiniu būdu iš Kauno specialiosios olimpiados klubo. Skirstant respondentes i tiriamaja ir kontroline grupes, atsižvelgta i jųužimtumq. Dvidešimt keturios riboto intelekto raidos merginos, nedalyvaujančios kitoje veikloje, buvo paskirtos $\dot{z}$ tiriamaja grupę, likusios dvylika dalyvavo kitoje papildomo ugdymo veikloje ir buvo paskirtos i kontrolinę grupę.

Testavimo būdu nustatytas bendrasis merginu fizinis pajègumas taikant Danijos bendrosios gimnastikos federacijos 1994 metais sukurta metodikq, skirta bendraja gimnastika kultivuojančiu asmenu bendrajam fiziniam parengtumui tirti (Course in general gymnastics, 1994).

Aerobikos pratybos ir ju metu sukurta palanki bendradarbiavimo su ugdytiniais aplinka yra veiksminga pedagoginio poveikio priemone, galinti skatinti ribotos intelekto raidos merginu fizinio pajègumo raida. Dèl ritminès gimnastikos pratybu poveikio gerejo tokie tiriamosios grupess ribotos intelekto raidos merginu fizinio pajègumo rodikliai kaip judesiu koordinacija, pusiausvyra, lankstumas, nugaros, pilvo, ranku, koju raumenu jèga (p < 0,001). Kontrolinejje grupejje reikšmingesniu fizinio pajègumo rodikliu pokyčio nepastebèta. Be to, tiriamosios grupés ribotos intelekto raidos merginu liemens jèga ir lankstumas nesiskyrè nuo nesutrikusios intelekto raidos bendraamžiu.

Raktažodžiai: ribota intelekto raida, fizinis pajègumas, ritminè gimnastika.

\section{IVADAS}

$\mathrm{P}$ astaruoju metu Lietuvoje vykdant švietimo reforma, visuomenè išgyvena ir sporto pokyčiu laikotarpi, keičiasi tiek mokslininku, tiek visuomenès požiūris i̇ ugdymą, jo reikšmę skirtingoms asmenų grupėms. Ypač didelị rūpestị vis dar kelia ribotos intelekto raidos asmenu integravimasis, jų gyvenimo kokybė ir ugdymas. Kadangi ilgą laiką vidutiniškai protiškai atsilikę vaikai ir jaunuo- liai buvo laikomi neugdytinais, jiems buvo skiriama tik medicinos priežiūra ir globa, o ugdymo ịstaigos buvo neprieinamos. Šiems jaunuoliams reikia specialios, visapusiškai jų asmenybę ugdančios bei rengiančios gyventi šių dienų kintančioje visuomenèje ugdymo programos, nes jų bendravimas ypač sudètingas ne tik dèl psichikos sutrikimu, bet ir dèl neišugdytos valios, sensomotorikos ribotumo. 
Kaip rodo praktika, daugelis pedagogu, dirbdami su ribotos intelekto raidos vaikais ir jaunuoliais, pastebi tam tikrų teigiamu jų fizinių ir asmenybès pokyčių. Šie pokyčiai gali atsirasti dèl įvairaus pobūdžio taikomosios veiklos (taikomosios fizinès, dailès, muzikos, rankdarbių ir kitos darbinès veiklos pratybu). Antai literatūroje nurodoma, kad svarbių pokyčių, ugdant ribotos intelekto raidos vaikus ir jaunuolius, galima pasiekti pritaikius individualias programas, kartu atsižvelgiant $i \mathrm{j} u$ gebejjimus (Faison-Hodge, Porretta, 2004; Onywadume, 2006). Visgi ugdant juos pagal pritaikytas programa, kyla klausimas, kaip jos turètų būti sudaromos. Todèl reikètu parbrèžti, kad vis dar stokojama tyrimų, kuriais būtų bandoma įvertinti taikomosios ritminès gimnastikos, kaip vieno iš taikomosios fizinès veiklos elemento, poveiki vidutiniškai protiškai atsilikusiems vaikams. Šie teiginiai paskatino imtis tyrimo ir kelti hipotezę, teigiančią, kad kryptingos ritminès gimnastikos pratybos ir su jomis susiję renginiai skatina ribotos intelekto raidos merginu fizinio pajègumo raida.

Tyrimo tikslas - nustatyti ritminès gimnastikos pratybu poveiki ribotos intelekto raidos merginu fiziniam pajègumui. Iškeltas tyrimo tikslas leido apibrèžti tyrimo uždavinius: 1) parengti ritminès gimnastikos pratybų programą ribotos intelekto raidos merginų fiziniam pajegumui gerinti; 2) atskleisti ribotos intelekto raidos merginu fizinio pajègumo pokyčius dèl ritminès gimnastikos pratybu poveikio.

\section{TYRIMO METODIKA IR ORGANIZAVIMAS}

Tyrimas buvo vykdomas nuo $2006 \mathrm{~m}$. rugsèjo iki 2007 m. gegužès mènesio. Ritminès gimnastikos programa tiriamajai grupei buvo taikoma 9 ménesius. Visą ši laikotarpi ritminès gimnastikos pratybos vyko tris kartus per savaitę. Buvo tiriamos ribotos intelekto raidos $18-25$ metu mergi$\operatorname{nos}(\mathrm{n}=36)$, pasirinktos atsitiktiniu netikimybiniu būdu iš Kauno specialiosios olimpiados klubo. Skirstant respondentes i tiriamają ir kontrolinę grupes, buvo atsižvelgiama i jų užimtumą. Dvidešimt keturios riboto intelekto raidos merginos, nedalyvaujančios kitoje veikloje, buvo paskirtos $i$ tiriamaja grupę, likusios dvylika dalyvavo kitoje papildomo ugdymo veikloje ir buvo paskirtos $i$ kontrolinę grupę. Tiriamosios grupès merginų amžius $-20,85 \pm 0,59$, kontrolinès $-21 \pm 0,6$ metu. Tiriamosios i grupes suskirstytos atsitiktinumo principu.
Testavimas. Testavimo būdu buvo nustatytas bendrasis merginu fizinis pajègumas. Remiantis kai kurių autoriu (Heyward, 1998; Winnick, Short, 1999; Winnick, 2005) tyrimais, buvo atlikti testai, kurie rodo ne vienpusišką fizini pajègumą, bet daugeli jo sudedamujų dalių. Raumenu jègai, ištvermei, širdies ir kraujagyslių sistemos fiziniam pajègumui tirti taikyta Danijos bendrosios gimnastikos federacijos $1994 \mathrm{~m}$. sukurta metodika, skirta bendrają gimnastiką kultivuojančių asmenu bendrajam fiziniam parengtumui tirti (Course in General Gymnastics, 1994). Tyrimui atlikti pasirinkti aštuoni testai (atsiseddimai, atsilenkimai, rankų lenkimas ir tiesimas, pašokimai, sulenktu kojų kèlimas, perlipimas per kėdę, peršokimas per suoliuką, $4 \mathrm{~m}$ bėgimas šaudykle), kurių kiekvieną reikejo atlikti kiek galima daugiau kartų per $30 \mathrm{~s}$. Šie testai yra pakankamai informatyvūs, nes jiems atlikti reikalingas greitis, ištvermè, jèga, be to, jų metu dirba visos didžiosios griaučių raumenu grupès.

Norint i̇vertinti šios metodikos tinkamumą ribotos intelekto raidos merginoms, šis testas buvo atliekamas du kartus per savaitę. Testo patikimumui nustatyti atlikti pakartotiniai matavimai. Triju testu — ranku tiesimo ir lenkimo, atsisėdimu bei bėgimo šaudykle patikimumas jau apskaičiuotas kitų autorių ir taikomas praktikoje testuojant protiškai atsilikusius asmenis (Heyward, 1998; Winnick, Short, 1999). C. M. Donncha ir kt. (1999) tyrimai parode, kad Eurofito testai yra tinkami taikyti protiškai atsilikusiems asmenims. Todèl sąnarių paslankumui tirti buvo naudojamas testas „Sèstis ir siekti“", o bendrai kūno pusiausvyrai nustatyti pasirinktas pusiausvyros stovint ant vienos kojos testas (Volbekienè, 1997).

Matematinè statistika. Tyrimo rezultatai apdoroti matematinès statistikos metodais, apskaičiuojant aritmetini vidurkị, standartini nuokrypi. Skirtumui tarp tiriamosios ir kontrolinès grupiu bei ritminès gimnastikos poveikio patikimumui nustatyti buvo taikytas Studento $t$ kriterijus.

\section{REZULTATAI}

Tyrimo pradžioje tiriamosios ir kontrolinès grupès merginų fizinio pajègumo, lankstumo bei pusiausvyros testų rezultatai buvo panašūs ir statistiškai reikšmingo skirtumo neaptikta. Tyrimo pabaigoje atliekant atsisėdimus pastebèta, kad tiriamosios grupès merginos atsisèdimu atliko daugiau nei eksperimento pradžioje $(\mathrm{p}<0,001)$, o kontrolinès grupès merginų rezultatai išliko pa- 


\begin{tabular}{|c|c|c|c|c|c|}
\hline \multirow{2}{*}{$\begin{array}{c}\text { Rodiklis } \\
\text { (kartai per } 30 \mathrm{~s})\end{array}$} & \multicolumn{2}{|c|}{ Tiriamoji grupè } & \multicolumn{2}{|c|}{ Kontrolinė grupè } & \multirow{7}{*}{$\begin{array}{l}\text { Lentelè. Tiriamųjų ben- } \\
\text { drojo fizinio pajègumo } \\
\text { rodiklių kaita }\end{array}$} \\
\hline & $\begin{array}{c}\text { Prieš eksperimentą } \\
(\bar{X} \pm \mathbf{S x})\end{array}$ & $\begin{array}{c}\text { Po eksperimento } \\
(\overline{\mathrm{X}} \pm \mathbf{S x})\end{array}$ & $\begin{array}{c}\text { Prieš eksperimentą } \\
(\bar{X} \pm \mathbf{S x})\end{array}$ & $\begin{array}{c}\text { Po eksperimento } \\
(\bar{X} \pm \mathbf{S x})\end{array}$ & \\
\hline Atsisèdimai & $10,85(1,45)$ & $17,23 *(0,64)$ & $11,45(1,22)$ & $10,82 * *(1,42)$ & \\
\hline Atsilenkimai & $12,46(1,68)$ & $17,23 *(1,37)$ & $11,36(2,28)$ & $12,55 * *(1,87)$ & \\
\hline Atsispaudimai & $9.0(0,72)$ & $16,67 *(0,80)$ & $7,91(0,86)$ & $8,45^{* *}(1,30)$ & \\
\hline Pašokimai & $24,83(2,13)$ & $29,42 *(1,76)$ & $23,91(2,29)$ & $22,82 * *(2,59)$ & \\
\hline $\begin{array}{l}\text { Sulenktų kojų kèlimo } \\
\text { kybant ant gimnastikos } \\
\text { sienelės rezultatai }\end{array}$ & $9,92(0,87)$ & $16,33 *(1,17)$ & $10,45(1,15)$ & $10,82 * *(0,96)$ & \\
\hline Perlipimas per kèdę & $8,92(0,72)$ & $12,92 *(0,85)$ & $7,73(1,08)$ & $7,55 * *(0,68)$ & \multirow{3}{*}{$\begin{array}{l}\text { Pastaba. } *-\mathrm{p}<0,01, \text { ly- } \\
\text { ginant tiriamosios grupes } \\
\text { reikšmes prieš eksperimenta } \\
\text { ir po jo; } * *-\mathrm{p}<0,001, \\
\text { lyginant tiriamosios ir kon- } \\
\text { trolinès grupès reikšmes po } \\
\text { eksperimento. }\end{array}$} \\
\hline $\begin{array}{l}\text { Peršokimo per suo- } \\
\text { liuką }\end{array}$ & $12,92(1,26)$ & $18,58 *(1,28)$ & $14,82(1,80)$ & $15,91 * *(1,83)$ & \\
\hline $4 \mathrm{~m}$ bėgimas šaudykle & $11,08(0,61)$ & $15,58 *(0,76)$ & $12,55(1,01)$ & $12,36^{* *}(1,00)$ & \\
\hline
\end{tabular}
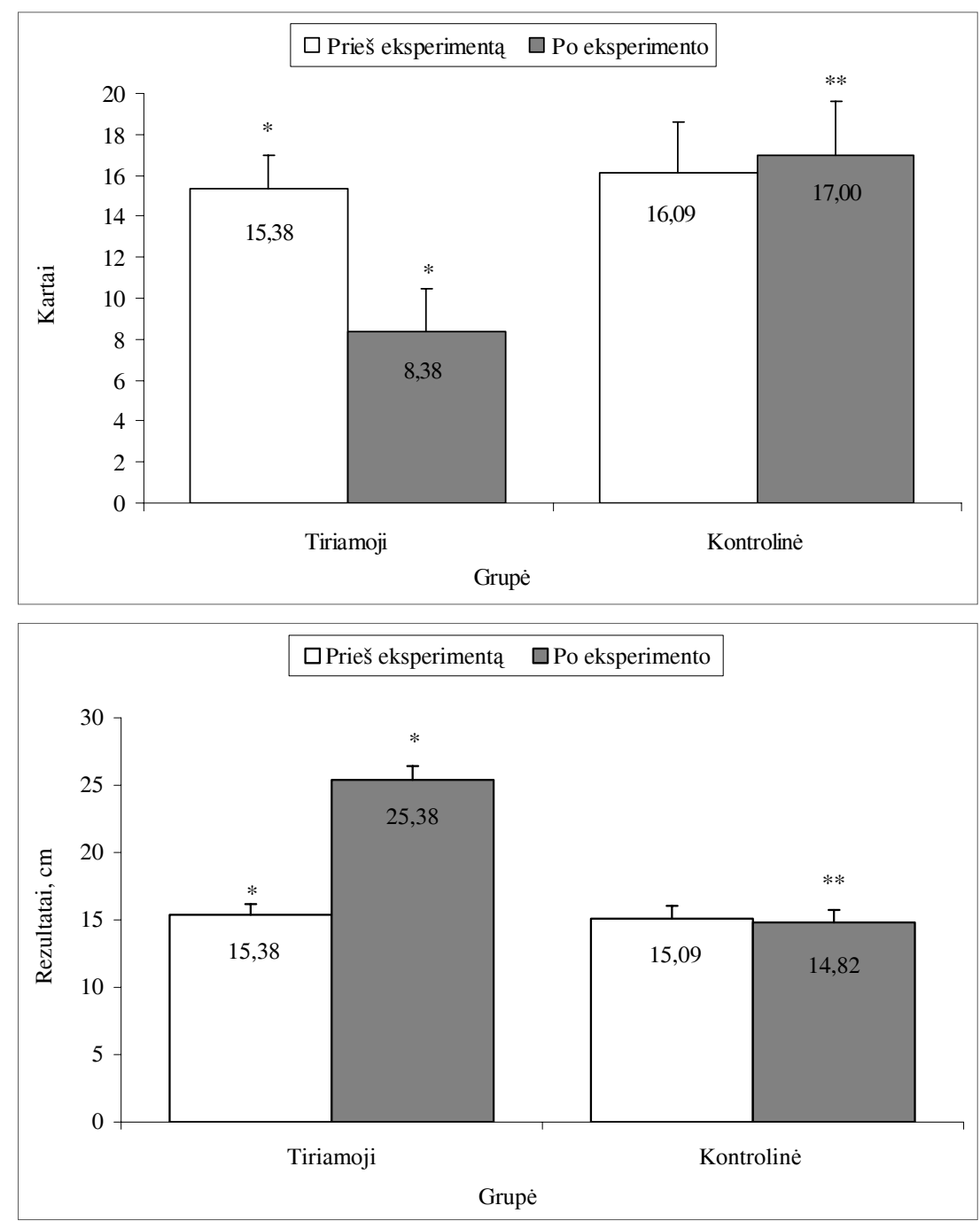

1 pav. Pusiausvyros testo rezultatai

Pastaba. * - p $<0,01$, lyginant tiriamosios grupès reikšmes prieš eksperimentą ir po jo; ** - $\mathrm{p}<0,001$, lyginant su tiriamosios ir kontrolinės grupės reikšmes po eksperimento.

\section{2 pav. Testo „Sėstis ir siekti“" rezultatai}

Pastaba. * - p $<0,01$, lyginant tiriamosios grupės reikšmes prieš eksperimentą ir po jo; $* *$ _ $p<0,001$, lyginant tiriamosios ir kontrolinès grupès reikšmes po eksperimento. našūs. Tiriamosios grupès merginų raumenų jèga buvo kur kas geresnè negu kontrolinès grupès merginu $(\mathrm{p}<0,001)$.

Atliekant atsilenkimus, kurie rodo nugaros raumenų jèga, tyrimo pabaigoje tiriamosios gru- pès merginų rezultatai labai pagerèjo ir reikšmingai $(\mathrm{p}<0,001)$ skyrèsi tiek nuo jų pačių tyrimo pradžioje pasiektų rezultatų, tiek nuo kontrolinès grupès tirtų merginų rezultatų. Atsispaudimų rezultatai eksperimento pabaigoje labai pagerèjo 
tiriamujų merginų grupès $(p<0,001)$, o kontrolinès grupès merginu rezultatai išliko beveik nepakitę. Rezultatai rodo, kad tyrimo pabaigoje buvo kur kas didesnè tiriamosios grupès merginų ranku raumenu jèga nei kontrolinès grupès $(\mathrm{p}<0,001)$. Atlikdamos pašokimus prie gimnastikos sienelès, tiriamosios grupés merginos baigus eksperimenta reikšmingai pagerino savo rezultatą $(\mathrm{p}<0,001)$, ir tai rodo ryškų kojų raumenu jègos didejjimą. Kontrolinès grupès merginos ši pratimą tiek prieš eksperimentą, tiek po jo atliko panašiai. Labai $(\mathrm{p}<0,001)$ pagerejo tiriamosios grupés merginu rezultatai keliant sulenktas kojas, kybant ant gimnastikos sienelès. Prieš eksperimentą kontrolinès ir tiriamosios grupès merginų rezultatai buvo panašūs, po eksperimento, skirtingai nei tiriamosios grupès, kontrolinės grupès šio pratimo atlikimo rezultatu pagerejjimo nepastebèta. Perlipimo per kèdę rezultatai po eksperimento reikšmingai $(\mathrm{p}<0,001)$ pagerejo tiriamosios grupès merginu, kontrolinès grupès - nepakito. Peršokimu per suoliuką rezultatus po eksperimento pagerino tik tiriamosios grupès merginos $(p<0,001)$, o kontrolinès rezultatai pakito nedaug. $4 \mathrm{~m}$ bègimo šaudykle rezultatai prieš eksperimentą ir po jo reikšmingai skyrèsi $(p<0,001)$ tik tiriamosios grupès merginų, o kontrolinès grupès - nesiskyrè. Eksperimento pabaigoje tiriamosios grupès merginos buvo daug šoklesnès, vikresnès ir greitesnès nei kontrolinès grupès merginos (žr. lent.).

Tiriamosios grupès merginu pusiausvyros rezultatai po eksperimento labai pagerejo, palyginti su rezultatais prieš ji $(\mathrm{p}<0,001)$. Aerobikos pratybas lankiusiu merginu pusiausvyros rezultatai pagerejo net iki 8,38 $\pm 2,09$ karto (kiek kartu per $30 \mathrm{~s}$ prarandama pusiausvyra). Kontrolinès grupès merginų rezultatai, kurie prieš eksperimentą buvo panašūs kaip ir tiriamosios grupès, atlikus eksperimentą išliko reikšmingai nepakitę $(p>0,05)$ (žr. 1 pav.).

Lankstumo testų rezultatai tiriamosios ir kontrolinès grupès prieš eksperimentą buvo panašūs. Po eksperimento tiriamosios grupès merginu lankstumo rezultatai reikšmingai pagerejo nuo $15,38 \pm 0,80$ iki $25,38 \pm 1,02 \mathrm{~cm}(\mathrm{p}<0,001)$ (žr. 2 pav.).

Kontrolinès grupès rezultatai išliko tokie pat ir net truputi sumažejo, lyginant su rezultatais tyrimo pradžioje (žr. 2 pav.).

\section{REZULTATŲ APTARIMAS}

Atlikti tyrimai parodè, kad dèl ritminès gimnastikos pratybų gerejo bendras merginų fizinis pajègumas. Pagerejo liemens, nugaros, ranku, kojų raumenu jèga, koordinacija, ištvermè, pusiausvyra, lankstumas. Gauti rezultatai patvirtina kitų autoriu tyrimų duomenis. Pavyzdžiui, J. Mikelkevičiūtè (2002) tyrimais nustatè, kad dèl taikomosios fizinès veiklos (sportiniu žaidimų) poveikio pagerejja lengvai protiškai atsilikusių paauglių lankstumas, pusiausvyra, liemens raumenu jèga. B. Boswell (1982) tyrimai rodo, kad dèl ritminès gimnastikos pratybu pagerèja dinaminè pusiausvyra ir ritminiai igūdžiai. Remiantis atliktų tyrimų rezultatais galima teigti, kad ritminè gimnastika, kaip viena iš taikomosios fizinès veiklos rūšiuc, tinka skirtingą riboto intelekto raidos laipsni turintiems žmonèms.

Tyrimai parode, kad nesportavusios ribotos intelekto raidos merginos savo fizinio pajègumo rezultatais atsilieka nuo normaliai besivystančiu bendraamžiuc, tačiau merginos, lankiusios aerobikos pratybas, labai pagerino savo rezultatus (Rèklaitienè ir kt., 1999). Liemens jèga buvo išlavinta kaip ir sveikujų bendraamžiu ir atitiko Eurofito nurodytas normas. Dauguma tyrimu rodo (Krebs, 1995; Winnick, 2005), kad protiškai atsilikę asmenys paprastai rodo prastesnius jègos, ištvermès, pusiausvyros, vikrumo, bėgimo greičio, lankstumo, reakcijos laiko rezultatus, palyginti su normalios raidos asmenimis. Lengvą intelekto sutrikimo laipsni turintys jaunuoliai pagal fizinio pajègumo testus gali drąsiai varžytis su normaliai besivystančiais bendraamžiais, o didesnio sutrikimo laipsnio asmenys atsilieka nuo sveikujų ketveriais ar daugiau metų. Yra pagrindo teigti, kad sveiki vaikai lenkia lengvą intelekto sutrikimo laipsni turinčius vaikus, kurie savo ruožtu yra pajègesni už vaikus, turinčius didesnio laipsnio protini atsilikimą (Eichstaedt, Lavay, 1992; Mikelkevičiūtè, 2002; Onywadume, 2006). Kaip parode eksperimento rezultatai, kryptingai lavinant fizines ypatybes, net ir didesnio laipsnio ribotos intelekto raidos merginos gali pasiekti normaliai besivystančių bendraamžių lankstumo ir pusiausvyros pajègumo lygi. Tai gali rodyti, kad viena iš riboto intelekto asmenu prasto fizinių užduočių atlikimo priežasčių yra ribotos galimybès ugdyti reikiamus motorinius igūdžius. Dèl šios priežasties nepakankamai susikuria judejjimo modelis, raumenys dar labiau nusilpsta, išryškejja koordinacijos nepakankamumas. 
Reikia pabrèžti, kad nors fizinio pajègumo testai atskleidè tam tikras fizines ypatybes, tačiau vidutiniškai protiškai atsilikusių merginų testų rezultatus daugiausia lèmè jų individualios psichologinès savybès, t. y. valios, ištvermès, gebėjimo susikaupti ir sutelkti dèmesi, motyvacijos atlikti testus poveikis. Ribotos intelekto raidos asmenys galūniu judesius atlieka lèčiau, maksimalaus greitèjimo ir lètejimo viršūnę taip pat jie pasiekia per ilgesni laiko tarpą nei normalaus intelekto (Choi et al., 1999). Sutrikusio intelekto asmenu yra kitoks judesio kontrolès mechanizmas, jie dažniau atsargiai stebi savo atsaką, dažnai reguliuoja judesị ir būtent todèl ilgejja judesio atlikimo laikas. Eksperimento metu taikyti fizinio pajègumo testai iš dalies parodè ir tiriamuju ištvermę. Reguliari fizinè veikla pagerina raumenu ištvermę ir jègą (Chanias et al., 1998; Onywadume, 2006), lankstumą (Pommering et al., 1994).

\section{IŠVADOS}

Aerobikos pratybos ir ju metu sukurta palanki bendradarbiavimo su ugdytiniais aplinka yra veiksminga pedagoginio poveikio priemonè, galinti skatinti ribotos intelekto raidos merginu fizinio pajègumo raidą.

Dèl ritminès gimnastikos pratybu gerèjo tokie tiriamosios grupès ribotos intelekto raidos merginu fizinio pajègumo rodikliai kaip judesių koordinacija, pusiausvyra, lankstumas, nugaros, pilvo, ranku, kojų raumenu jèga $(\mathrm{p}<0,001)$. Kontrolinèje grupejje reikšmingesniu fizinio pajëgumo rodikliu pokyčio nepastebèta. Tiriamosios grupès ribotos intelekto raidos merginu liemens jèga ir lankstumas nesiskyrè nuo nesutrikusios intelekto raidos bendraamžių.

\section{LITERATŪRA}

Boswell, B. (1982). Adapted Dance for Mentally Retarded Children: An Experimental Study: Doctoral Dissertation. Texas: Texas Woman's University.

Chanias, S., Reid, G., Hoover, H. (1998). Exercise effects on health-related physical fitness of individuals with an intellectual disability: A meta-analysis. Adapted Physical Activity Quarterly, 15, 119-140.

Choi, S., Meeuwsen, H. J., French, R., Stenwall, J. (1999). Learning and control of simple aiming movement by adults with profound mental retardation. Adapted Physical Activity Quarterly, 16, 167-177.

Course in General Gymnastics. (1994). Densk Gymnastics Forhend. Vilnius, October, P. 126.

Donncha, C. M., Watson, A. W. S., McSweeney, T., O‘Donovan, D. J. (1999). Reliability of Eurofit physical fitness items for adolescent males with and without mental retardation. Adapted Physical Activity Quarterly, 16, $86-95$.

Eichstaedt, C. B., Lavay, B. W. (1992). Physical Activity for Individuals With Mental Retardation. Human Kinetics.

Faison-Hodge, J., Porretta, D. (2004). Physical Activity Levels of Students with Mental Retardation and Students without Disabilities. Adapted Physical Activity Quarterly, $21,139-152$.

Heyward, V. H. (1998). Advanced Fitness Assessment Exercise Prescription. Human Kinetics.

Krebs, P. L. (1995). Mental Retardation. Adapted Physical Education and Sport. New York: State university of New York college at Brockport. Human Kinetics. P. 99-105.
Mikelkevičiūtè, J. (2002). Taikomosios fizinès veiklos poveikis nežymiai protiškai atsilikusiu paaugliu savęs vertinimui ir fizinès kompetencijos suvokimui: daktaro disertacija. Kaunas: LKKA.

Onywadume, I. (2006). Fitness of Black African early adolescents with and without mild mental retardation. Adapted Physical Activity Quarterly, 23 (3), 167-177.

Pommering, T., Brose, J., Randolph, E. et al. (1994). Effects of an aerobic exercise program on community-based adults with mental retardation. Mental Retardation, 32 (3), $218-226$.

Rèklaitienè, D., Macaitienè, A., Bagočiūnas, S. (1999). Aerobikos treniruočiu poveikis sutrikusio intelekto bei sveiku 16-20 metu merginu bendrajam fiziniam parengtumui ir vestibulinei funkcijai. Taikomoji fizine veikla ir neigaliuju socializacija: problemos ir perspektyvos. Tarptautines mokslines konferencijos medžiaga (pp. 51-53). Kaunas: LKKA.

Volbekienè, V. (1997). Eurofit'o testai suaugusiems: metodiné priemoné. Vilnius.

Winnick, J. P. (2005 ). Conceptual framework for the Brockport physical fitness test. Adapted Physical Activit Quarterly, 22, 323-333.

Winnick, J. P., Short, F. X. (1999). The Brockport Physical Fitness Test Manual. A Health-Related Test for Youths With Physical and Mental Disabilities. Human Kinetics. 


\title{
ALTERNATION OF PHYSICAL FITNESS OF GIRLS WITH MENTAL RETARDATION AFFECTED BY RHYTHMIC GYMNASTICS
}

\author{
Diana Rèklaitienè, Jūratė Požèrienè \\ Lithuanian Academy of Physical Education, Kaunas, Lithuania
}

\begin{abstract}
Recently, when our society has been undergoing a fast period of changes, the attitude towards education and its significance for different groups of people has changed among scientists, as well as other people in the society. Participation in sport by individuals with intellectual disabilities has increased considerably as well. As practice shows, physical health and fitness of the girls with mental retardation could be improved working accordingly to specially adapted programs. But there is little research about the impact of rhythmic gymnastics on the development of girls with mental retardation.

The aim of the research was to determine an effect of rhythmic gymnastics programme on physical fitness of girls with mental retardation.

Organization and methods of the research. The research group consisted of 36 girls with mental retardation. The experimental group included 24 girls with mental retardation and the control group included 12 girls with mental retardation. Research was organized during the period from September, 2006 to May, 2007. The sessions of rhythmic gymnastics were applied 3 times per week during a 9 months period.

Physical fitness was tested by the method, designed by Danish Gymnastics Federation in 1994. The method involved 8 different tests designed to assess muscle strength and endurance, another "sit and seek" test was used to test flexibility. Balance test was applied to evaluate the balance function. The mean score, standard deviation and Student $(\mathrm{t})$ criteria were used for data analysis.

Research results. There were no significant differences between various indicators of physical fitness of subjects in the experimental and control groups at the beginning of the study. The results showed that rhythmic gymnastics programme had positive influence on such physical fitness indicators as movement coordination, balance, flexibility, strength of the trunk, muscles of arms and legs. There were no significant changes in physical fitness of the girls from the control group.
\end{abstract}

Keywords: development of intellect of persons with mental retardation, physical fitness, rhythmic gymnastics.

Gauta 2008 m. gegužès 1 d.

Received on May 1, 2008

Priimta $2008 \mathrm{~m}$. birželio $18 \mathrm{~d}$.

Accepted on June 18, 2008

Diana Rèklaitienè

Lietuvos kūno kultūros akademija

(Lithuanian Academy of Physical Education)

Sporto g. 6, LT-44221 Kaunas

Lietuva (Lithuania)

Tel +370 37302660

E-mail d.reklaitiene@lkka.lt 